\title{
High Counting Rate Resistive-Plate Chamber
}

\author{
V. Peskov, D.F. Anderson and S. Kwan \\ Fermi National Accelerator Laboratory \\ P.O. Box 500, Batavia, Illinois 60510
}

\begin{abstract}
DISET AIMER
This report was prepared as an account of work sponsored by an agency of the United States Government. Neither the United States Government nor any agency thereof, nor any of their employees, makes any warranty, express or implied, or assumes any legal liability or responsibility for the accuracy, completeness, or usefulness of any information, apparatus, product, or process disclosed, or represents that its use would not infringe privately owned rights. Reference herein to any specific commercial product, process, or service by trade name, trademark, manufacturer, or otherwise does not necessarily constitute or imply its endorsement, recommendation, or favoring by the United States Government or any agency thereof. The views and opinions of authors expressed herein do not necessarily state or reflect those of the United States Government or any agency thereof.
\end{abstract}

May 1993

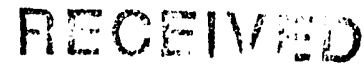

JUN 141993

$0 \mathrm{OTI}$ 


\section{Disclaimer}

This report was prepared as an account of work sponsored by an agency of the United States Government. Neither the United States Government nor any agency thereof, nor any of their employees; makes any warranty, express or implied, or assumes any legal liability or responsibility for the accuracy, completeness, or usefulness of any information, apparatus, product, or process disclosed, or represents that its use would not infringe privately owned rights. Reference herein to any specific commercial product, process, or service by trade name, trademark, manufacturer, or otherwise, does not necessarily constitute or imply its endorsement, recommendation, or favoring by the United States Government or any agency thereof. The views and opinions of authors expressed herein do not necessarily state or reflect those of the United States Government or any agency thereof. 
TM-1838

April 1993

\title{
High Counting Rate Resistive-Plate Chamber
}

\author{
V. Peskov, D.F. Anderson, and S. Kwan \\ Particle Detector Group \\ Fermi National Accelerator Laboratory \\ Batavia, II 60510
}

\section{Introcuction}

Parallel-plate avalanche chambers (PPAC) are widely used in physics experiments because they are fast $(<1 \mathrm{~ns})$ and have very simple construction: just two parallel metallic plates or mesh electrodes (see ref. 1 as an example). Depending on the applied voltage they may work either in spark mode or avalanche mode (see for example [2]). The advantage of the spark mode of operation is a large signal amplitude from the chamber, the disadvantage is that there is a large dead time (msec) for the entire chamber after an event. The main advantage of the avalanche mode is high rate capability $10^{5}$ counts $/ \mathrm{mm}^{2}[3]$.

A resistive-plate chamber (RPC) is similar to the PPAC in construction except that one or both of the electrodes are made from high resistivity $\left(\geq 10^{10} \Omega \bullet \mathrm{cm}\right)$ materials. In practice RPCs are usually used in the spark mode. Resistive electrodes are charged by sparks, locally reducing the actual electric field in the gap. The size of the charged surface is about $10 \mathrm{~mm}^{2}$, leaving the rest of the detector unaffected. Therefore, the rate capability of such detectors in the spark mode is considerably higher than conventional spark counters. In early designs of RPCs [4], the electrodes were made from glasses. Among the different glasses tested the best results were obtained with electron type conductive glasses [5], which obey Ohm's law. Most of the work with such glasses was done with high pressure parallel-plate chambers $(10 \mathrm{~atm})$ for time-of-flight measurements [6]. Resistive glasses have been expensive and produced only in small quantities thus their application scale has been very limited. This is why recent RPCs used phenolic (Bakelite) and other polymers rather than resistive glasses [7]. These materials do not 
obey Ohm's law, with the resistivity depending on the applied voltage and time. Nevertheless, at low counting rate $\left(<100 \mathrm{~Hz} / \mathrm{cm}^{2}\right)$ they are quite stable. At present, the main application of such chambers is muon detection.

Since the earlier days of the RPC, a lot of changes have occurred. Now resistive glasses are commercially available [8], although they are still expensive in a small scale production and used primarily for gas microstrip detectors [9]. From the positive experience of different groups working with the resistive glasses [10], we decided to review the old idea to use this glass for the RPC. We have mainly investigated the possibility of using the RPC at 1 atm and in the avalanche mode of the operation. This has several advantages: simplicity of construction, high rate capability, low voltage operation, and the ability to work with non-flammat :e gases. We present our preliminary work here.

\section{Experimental set-up}

The experimental set-up is shown on fig. 1. In general it consists of a RPC, gas system, well collimated beta source, a trigger scintillator with PMT, and associated electronics. In order to make a comparison of different techniques three types of RPC were studied: 1) phenolic, 2) resistive glass, and 3) constructed from conductive pads isolated by resistors. Both types 1 and 2 were tested with and without spacers between the two electrodes to study their effect on counting characteristics - Two different gaps between the electrodes were tested: $1.3 \mathrm{~mm}$ and $2 \mathrm{~mm}$. Gas mixtures tested were: $\mathrm{Ar}+$ iso- $\mathrm{C}_{4} \mathrm{H}_{10}$, Artiso- $\mathrm{C}_{4} \mathrm{H}_{10}+$ freon, Ar+iso- $\mathrm{C}_{4} \mathrm{H}_{10}$ tethane, $\mathrm{Ar}+\mathrm{CH}_{4}, \mathrm{He}$ and $\mathrm{Xe}+\mathrm{iso}-\mathrm{C}_{4} \mathrm{H}_{10}$ and $\mathrm{CH}_{4}$ all at a total pressure of $1 \mathrm{~atm}$.

In one configuration (fig. $2 \mathrm{a}$ ) either one or both electrodes were made from phenolic polymers. The electrodes were $3 \mathrm{~mm}$ thick and $10 \mathrm{~cm}$ in diameter. The middle part of one of the electrode was thinned to $0.5 \mathrm{~mm}$ in order to be transparent for betas from the external source.

In a second configuration (fig. $2 b$ ) the lower electrode (anode) was made from a $10 \times 10 \times 0.2 \mathrm{~cm}^{3}$ piece of resistive glass. Electron conductive glasses with resistivities of $10^{9} \Omega \bullet \mathrm{cm}$ and $10^{10} \Omega \bullet \mathrm{cm}$ were tested. The cathode was a well polished aluminum plate, which had a thin spot $(0.2 \mathrm{~mm})$ in the middle.

The third configuration (fig. $2 \mathrm{c}$ ) was tesțed in order to study minimum dead times and the length of propagation of VUV photons, able to produce secondary sparks, in different gas mixtures. The pad size was $5 \times 5 \mathrm{~mm}^{2}$ with gap widths of $1 \mathrm{~mm}$ and $1.5 \mathrm{~mm}$. Each pad of one plane was isolated by resistors of $0.1-1 \mathrm{G} \Omega$. 
As sources of primary ionization we used a beta source $\left({ }^{90} \mathrm{Sr}\right)$, gamma sources ( $60 \mathrm{Co}$ and $\left.{ }^{22} \mathrm{Na}\right)$, cosmic muons, and UV radiation from a mercury lamp. In the last case a special electrode was used with a small hole covered by quartz window (fig. $2 d$ ). This configuration was somewhat different than shown in fig. 1 with the top electrode being part of the outside chamber wall.

Signals from the chambers in the spark mode were observed directly on the oscilloscope $(50 \Omega)$ and in parallel were shaped and analyzed by a PHA. In the avalanche mode the signals were amplified, shaped, and analyzed by a pulse-height analyzer, PHA.

The work that is presented here is based primarily on constructions without spacers. This is because the introduction of spacers to the design increased the leakage current and produced spurious pulses that have been seen by others [5].

\section{Measurements}

The timing resolution of the PPAC, glass and phenolic RPCs have been measured by many authors in both the spark and avalarthe mode (see for example ref.[11-14]) and is rather well established. For 1-2 mm gaps, and a typical gas pressure of $1 \mathrm{~atm}$, the timing resolution is usually $0.35-0.5 \mathrm{~ns}$ in the spark mode and 2-3 ns in the avalanche mode. This timing resolution is determined by the development the avalanche in the gap and therefore resistive electrodes (at low rates) do not affect these results. For this reason we assumed that the time resolution of our detector is the above quoted value and we concentrated on the measurements of the other important characteristics: detection efficiency, counting rate capability, stability, dark current, and uniformity of the response. The efficiency was measured by comparison the counting rate from the RPC and the trigger scintillator and thus should be considered a lower limit.

\section{Results}

Typical oscilloscope pictures of signals from the resistive-glass RPC in avalanche and spark mode are presented on fig. $3 \mathrm{a}, \mathrm{b}$. In the avalanche mode, sufficient gain was achieved to observe the signal directly on the $50 \Omega$ input of the oscilloscope (see fig. 3 ). The rise time of the current pulse is about $5 \mathrm{~ns}$.

When the voltage was increased spark pulses were observed. The typical shape of the spark pulse can be seen in fig. 3b. The rise time is about 3 ns and fall time is $50-100$ ns. The typical amplitude is about $1 \mathrm{~V}$. In most cases this spark pulse was preceded by a precursor pulse, as shown in fig. 3d. The spark delay time (if the precursor is taken as the start) fluctuated rather strongly (order of a few ns). 
In the case of the phenolic RPC similar pulses were observed, but increasing the counting rate in the avalanche mode or the operating voltage to the spark mode caused a very long dead time: a few minutes to hours. It is not known if other authors observed this effect since it is not mentioned in the literature. The efficiency of a resistive-glass RPC, operated in avalanche and spark modes, as function of voltage for the relatively small counting rate $(100 \mathrm{~Hz})$ is presented in fig. 4. Efficiencies as a function of rate is shown in fig. 5 for both phenolic and resistive-glass RPCs operated in the spark mode. Fits from ref. 15 and ref. 16 are included as a comparison. The counting rate capability of the resistive-glass RPC operated at two different gains in the avalanche mode is presented in figs. $6 \mathrm{a}$ and $6 \mathrm{~b}$. By comparing figs. 5 and 6 one can conclude that counting rate capability of resistive-glass RPC is better than our phenolic RPC.

Other important feature of the avalanche mode is that the chamber can work with a wide variety of gas mixtures, including non-flammable mixtures (for details see ref[2]). For example the chamber was very stable when operated with a mixture of $\mathrm{Ar}+\mathrm{few}$ $\% \mathrm{CH}_{4}$.

Measurements with the pad RPC show that the minimum dead time necessary for the full suppression of the secondary processes after the spark is a few ms. If the time constant of the circuit is about the same the detector works as well as the resistive-glass RPC. The mean free path of the active VUV photons depends strongly on the gas composition and in the best case $\left(\mathrm{Ar}+\mathrm{iso}-\mathrm{C}_{4} \mathrm{H}_{10}+\right.$ ethane) was about $1-2 \mathrm{~mm}$.

\section{Discussion}

Results obtained lead us to believe that the resistive-glass RPC has a much better counting rate characteristics then one with polymers having the ionic type of the conductivity. In the streamer mode the pulse amplitude is a factor of two larger than a normal RPC. Recovery time is stable: it is independent of the applied voltage and the ionization source intensity. The quality of the glass surface is extremely good so the mechanical tolerance is much better than for phenolic. Without spacers no spurious pulses were seen. The design of a large PPAC without spacers has been developed by the authors of the ref [17].

In the avalanche mode of the operation the RPC has an excellent counting rate capability. With the detector operated in the avalanche mode a total charge of $10^{8}$ electrons per pulse was achieved. This value depends slightly on the gas mixture and has little dependence on the primary charge (see fig. 7 from ref. [2]). For a large initial charge, the RPC goes into spark mode which may be a problem in a hadron environment where there is a substantial flux of neutrons. In the usual PPAC, sparks disturb normal 
operation and affects the measuremenis. In the phenolic RPC sparks can interrupt the normal operation for 20-30 min. In the resistive-glass RPC sparks do not strongly affect the normal operation and therefore working in the avalanche mode with the occasional sparks is acceptable. So in this marginal regime (with occasional sparks) which people tried to avoid before becomes very practical. We should note that any PPAC at high gain and high counting rate has some spark probability. This is illustrated by the curve, presented in fig. 8 (from ref.[18]). Sparks occurs when two avalanches statistically overlaps in space [2].

Early work used a "Pestov gas mixture" (Ar+butane+Ethylene+1,3 Butadiene) which is very quenching due to the strong absorption of the photons with wavelength less than $220 \mathrm{~nm}$. This gas mixture seems to be more essential in the case of phenolic RPC because the propagation of the discharge will charge the electrodes and will lead to the long recovery time. A highly quenching gas mixture is much less essential in the case of the resistive-glass RPC. As we mentioned before in the avalanche mode glass RPC can work in a wide variety of gases including non flammable mixtures which are important for many applications.

In Table 1 we compare the properties of the phenolic and resistive-glass RPCs. One can clearly see the advantages of the resistive glass RPC.

\section{Future plans for study}

We plan to study precursor pulses in order to understand their timing characteristics.

We plan to study resistive-glass a RPC with a CsI secondary electron emitter. Our recent study shows that under certain conditions the CsI cathode in the PPAC produces secondary electrons. This should improve the timing properties of the detector.

We will study resistive-glass a RPC with anode strips as alternative to gas microstrip detectors.

Aging studies need to be done.

The work of high-pressure, resistive-glass RPC will be studied for the application of time-of-flight measurements.

\section{Conclusion}

The resistive-glass RPC can operate in both spark and avalanche modes. The advantages of the avalanche mode are: high rate capability, stability, low operating voltage, and the ability to use non-flammable gases. The resistive glass is rigid and 
which allows the minimization of the number of spacers to be used in the construction. The electrodes can be easily polished and this improves the operating characteristics.

In the spark mode the resistive-glass RPC is more stable than the phenolic RPC and has better counting rate capability. Unfortunately the price of the resistive glasses is still higher than phenolic polymers. On the other hand this price is comparable to plastic scintillators (plus the PMT) and this makes it attractive as a trigger for muons.

More research is still needed to demonstrate that glass RPC are competitive with phenolic in a large-scale detector. Such parameters as performance, stability, and cost will be considered.

\section{Acknowledgments}

This work was inspired by discussion with i)r. B. Atwood who worked with high pressure resistive-glass RPC for time-of-flight mea iurements. We thank him for the advice and for supplying us with resistive glass.

\section{References}

1. K. Kleinknech!, "Detectors for particle radiation", Cambr. Univ. Press, 1985

2. P. Fonte, et al., NIM A305 (1991) 91.

3. A. Peisert NIM 217 (1983) 409.

4. M.V. Babykin, et al., Sov. Journ. of Atomic Energy 4 (1956) 487; V.V. Parhomchuk, et al., NIM 93 (1971) 269.

5. Yu. Pestov, private communication.

6. B. Atwood, Preprint SLAC-PUB-2620 1980, Yu. Pestov, Preprint NIP 90-83, Novosibirsk, 1990.

7. R. Santonico, et al., NIM 187 (1981) 377.

8. B. Atwood, private communication.

9. R. Bouclier, et al., NIM A323 (1992) 240.

10. G.D. Minakov, et al., NIM A326 (1993) 566, R. Bouclier et al., Preprint CERNPPE/93-04, 1993.

11. V. Peskov, unpublished data, CERN 1992.

12. E. Gorini, et al., Report at Fermilab's Dir. Rev., March 31993

13. O. Gardes, preprint Orsay IPNO-RC-81-05, Univ.Paris Sud 1981.

14. Results from L3P Collaboration NIM A325 (1993) 23.

15. M. Bertino, et al., NIM A283 (1989) 645.

16. I. Crotty, et al., Preprint CERN/PPE92-182, 1992.

17. Yu. Galaktionov, et al., Preprint CERN-PPE/91-148, 1991. 

C. Gruhn, et al., NIM A247 (1986) 460.

Table 1: Properties of the phenolic and resistive-glass RPC.

\begin{tabular}{|c|c|c|c|}
\hline 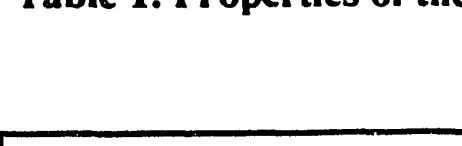 & $\begin{array}{c}\text { Phenolic } \\
\text { (spark) }\end{array}$ & $\begin{array}{c}\text { Resistive glass } \\
\text { (spark) }\end{array}$ & $\begin{array}{c}\text { Resistive glass } \\
\text { (avalanche) }\end{array}$ \\
\hline Pulse height & $100-300 \mathrm{mV}$ & $\leq 1 \mathrm{~V}$ & $10^{7} e^{-}$ \\
\hline Pulse length (ns) & 20 & $20-50$ & 10 \\
\hline Rise time (ns) & $5-10$ & $5-10$ & 5 \\
\hline Resistivity $(\Omega \bullet \mathrm{cm})$ & $10^{11}$ & $10^{10}-10^{11}$ & $10^{10}$ \\
\hline External field $(\mathrm{kV} / \mathrm{cm})$ & $40-50$ & $40-50$ & $10-20$ \\
\hline Recovery time (ms) & 10 & 10 & $\ll 0.1$ \\
\hline Dead area $\left(\mathrm{mm}^{2}\right)$ & 10 & 10 & $\ll 10$ \\
\hline Efriciency (\%) & $\approx 96$ & $\approx 97$ & $\approx 95$ \\
\hline Plateau (kV) & 1 & 1 & $1-2$ \\
\hline Dark current $(\mu A)$ & $50^{\dagger}$ & 0 & 0 \\
\hline $\begin{array}{l}\text { Rate at } 87 \% \text { efficiency } \\
\left(\mathrm{Hz} / \mathrm{cm}^{2}\right)\end{array}$ & 100 & 200 & 2000 \\
\hline Timing resolution (ns) & 0.5 & 0.35 & $2-3$ \\
\hline Gas mixture & $\begin{array}{l}\mathrm{Ar}+\mathrm{i}-\mathrm{C}_{4} \mathrm{H}_{10} \\
\quad \text { +freon }\end{array}$ & $\begin{array}{c}\mathrm{Ar}+\mathrm{i}-\mathrm{C}_{4} \mathrm{H}_{10}+\text { freon } \\
\text { or } \\
\mathrm{Ar} \\
\mathrm{s}+ \\
\mathrm{i}-\mathrm{C}_{4} \mathrm{H}_{10}+\text { ethane } \\
\text { +butadiene } \\
\end{array}$ & $\mathrm{Ar}+\mathrm{CH} 4$ \\
\hline
\end{tabular}

$\dagger$ In this configuration spacers were used which gave rise to the high current. 


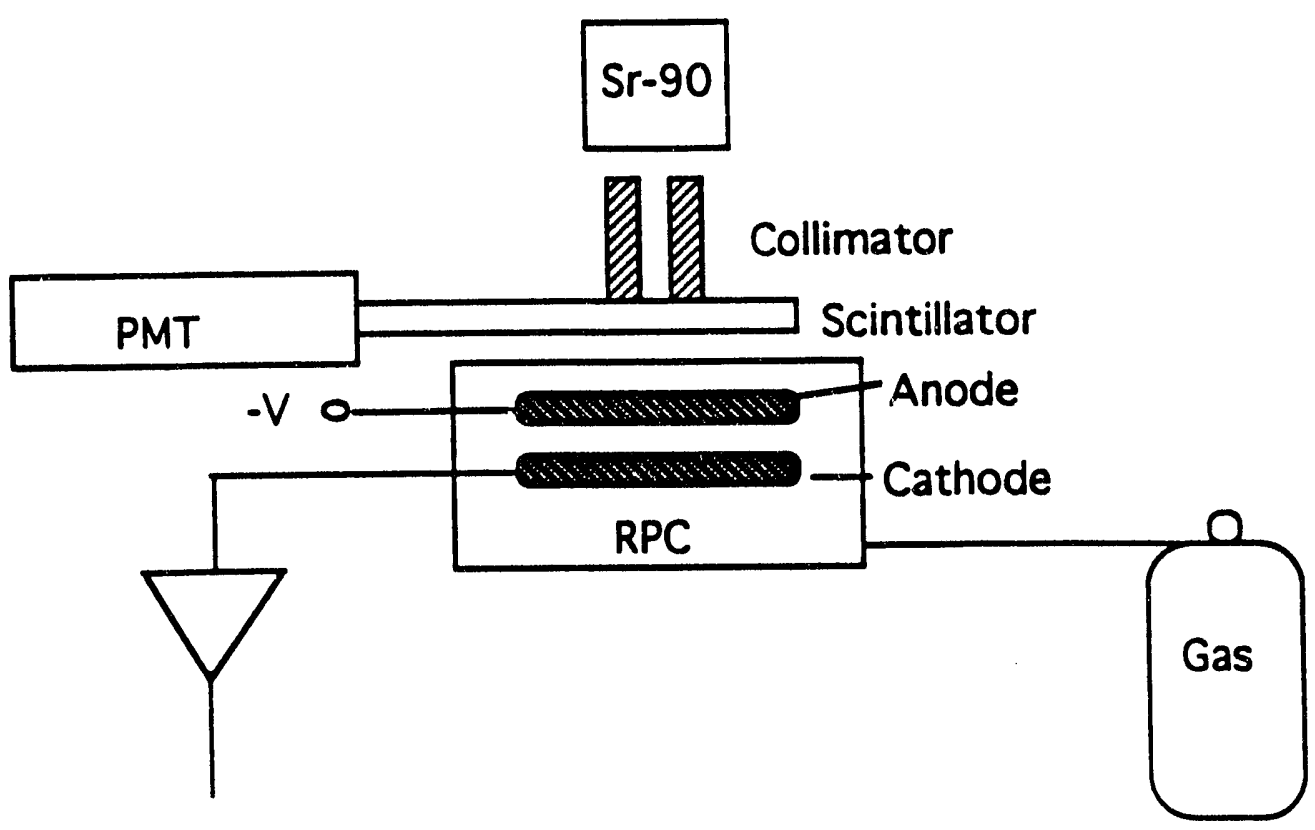

Fig.1 Experimental set-up

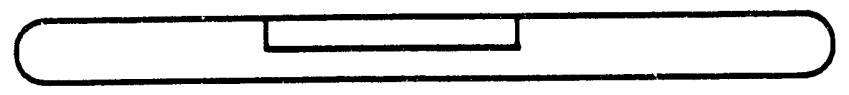

a

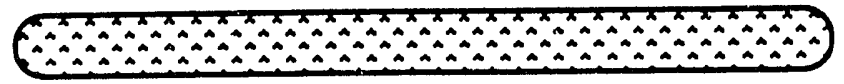

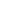

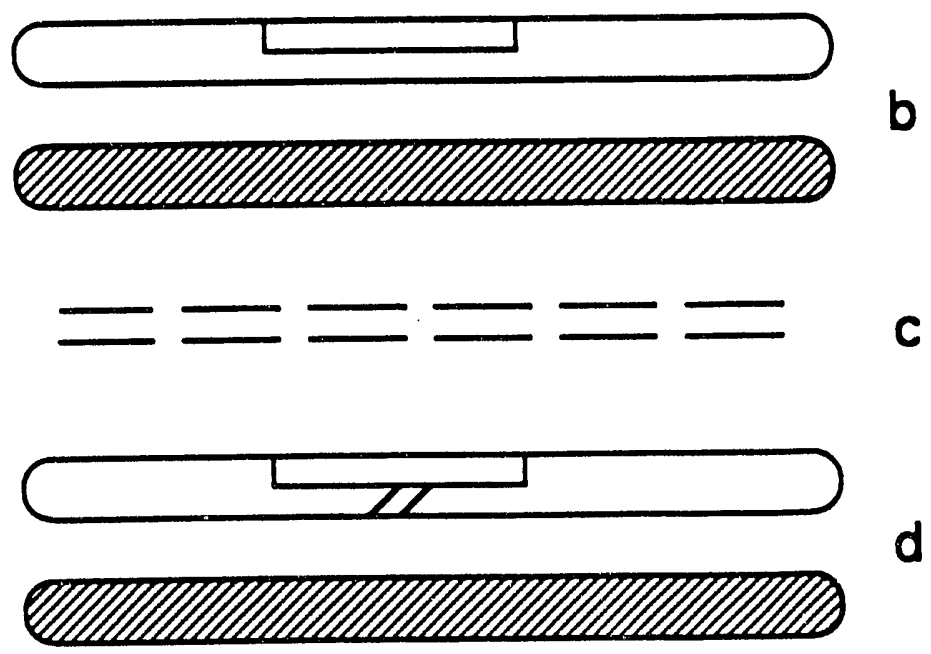

Fig. 2 Construction of electrodes for the different RPC tested a) phenolic RPC,

b) glass RPC, d) glass RPC with the window transparent for UV, c) pad RPC 

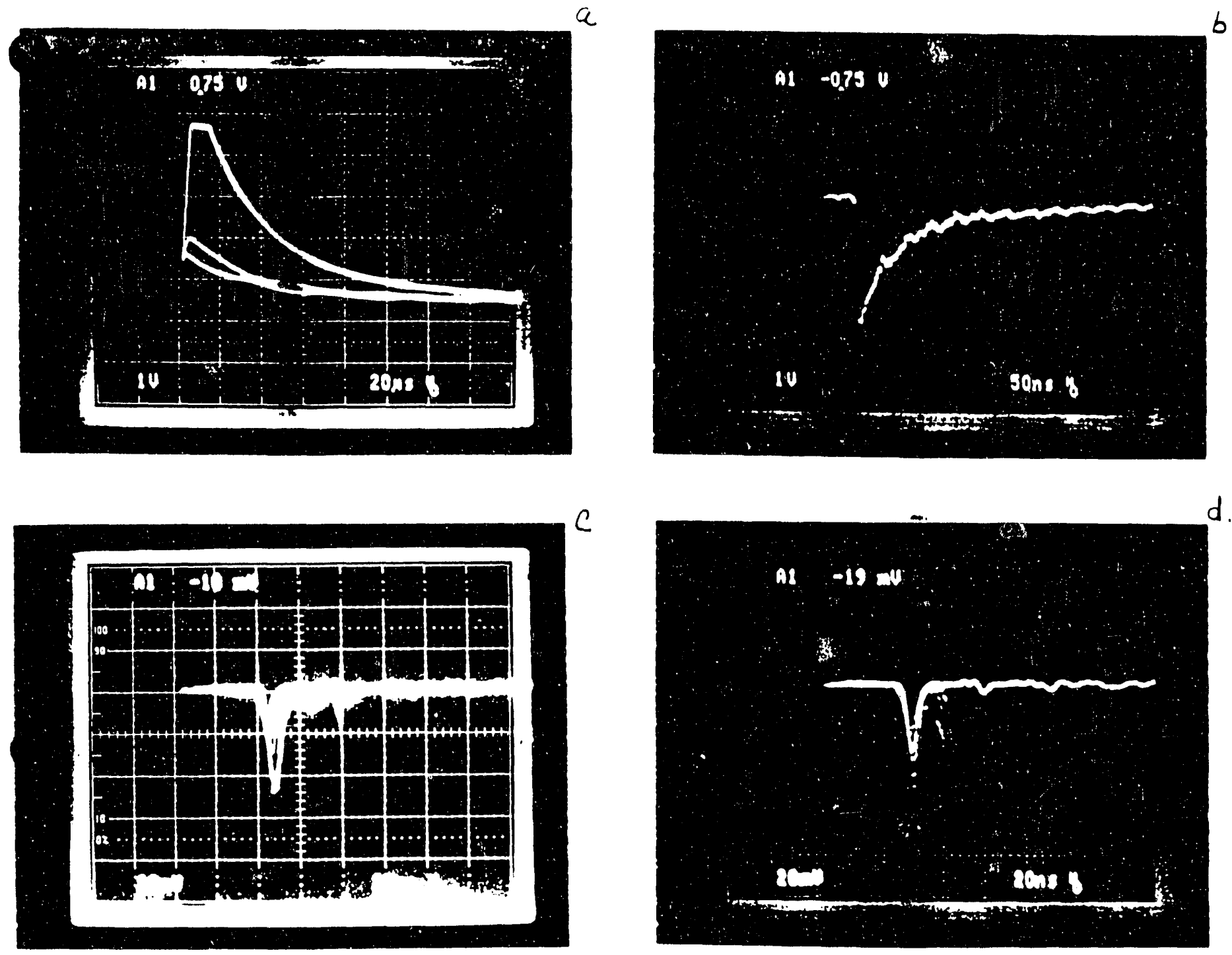

Fig 3 Typical oscilloscope pictures of signals from the glass RPC: a) Typical shape of signals after the preamplifier, b) signal, prociuced by the spark directly on the $50 \Omega$ input of the scope, c) avalanche signal on the $50 \Omega$ input of the scope, d) precursors and sparks together 


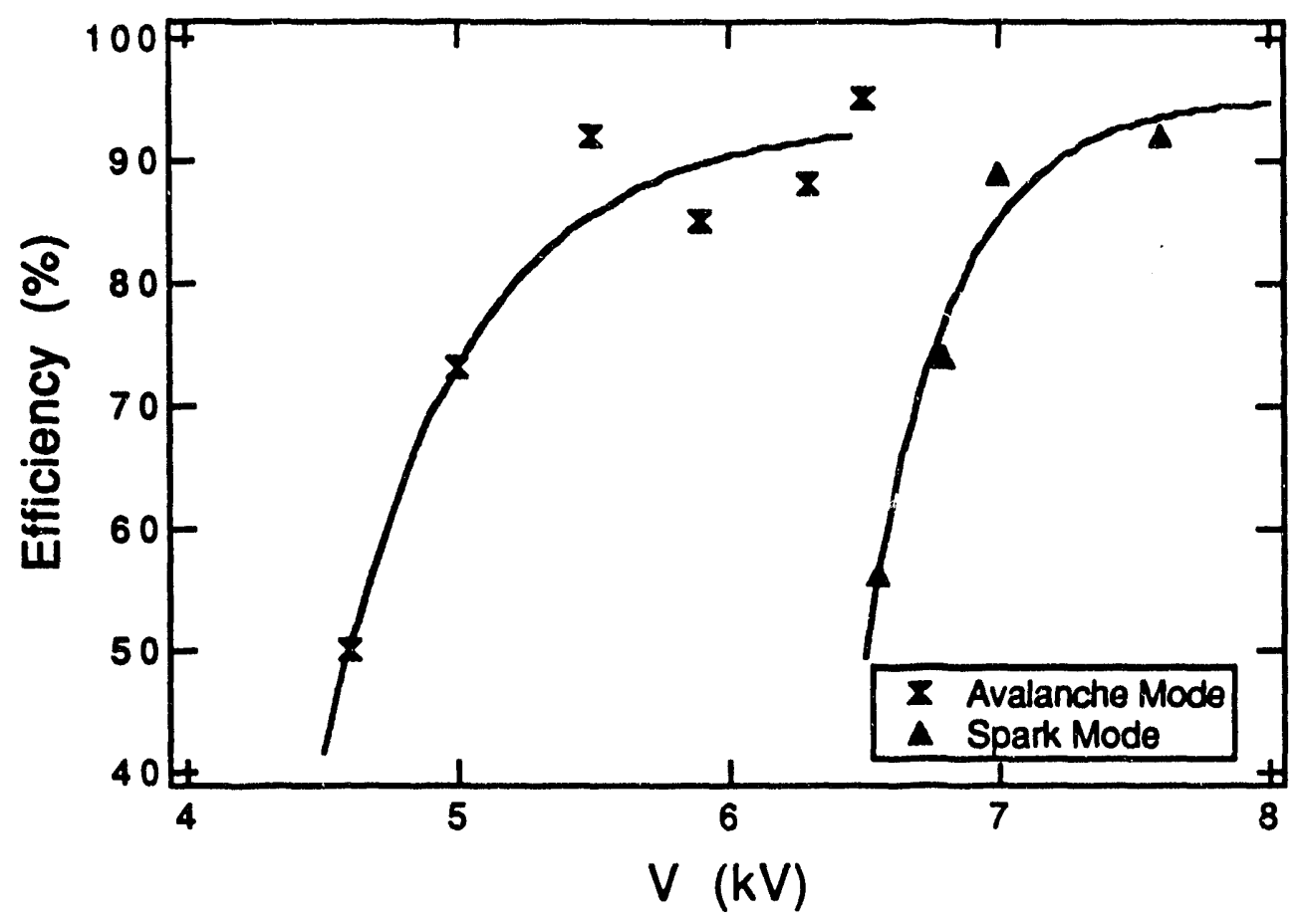

Fig. 4 Efficiency of the glass RPC in avalanche and spark mode. The gas mixture: Ar +isob+freon. Gap $2 \mathrm{~mm}$.

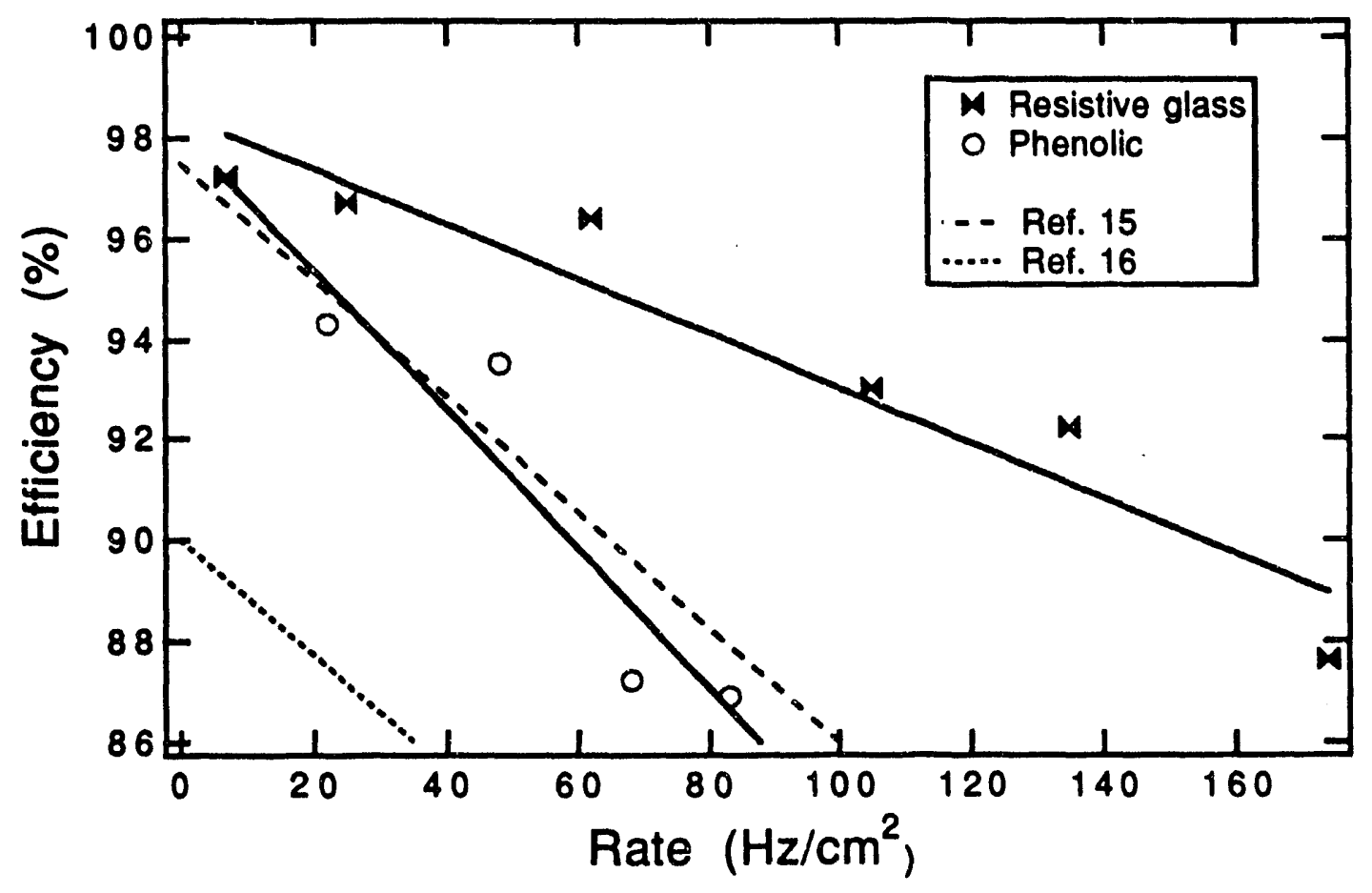

Fig. 5 Efficiency of the glass and phenolic RPC versus counting rate. For the comparison data from the other authors are presented (Ref. 15 and Ref. 16). 


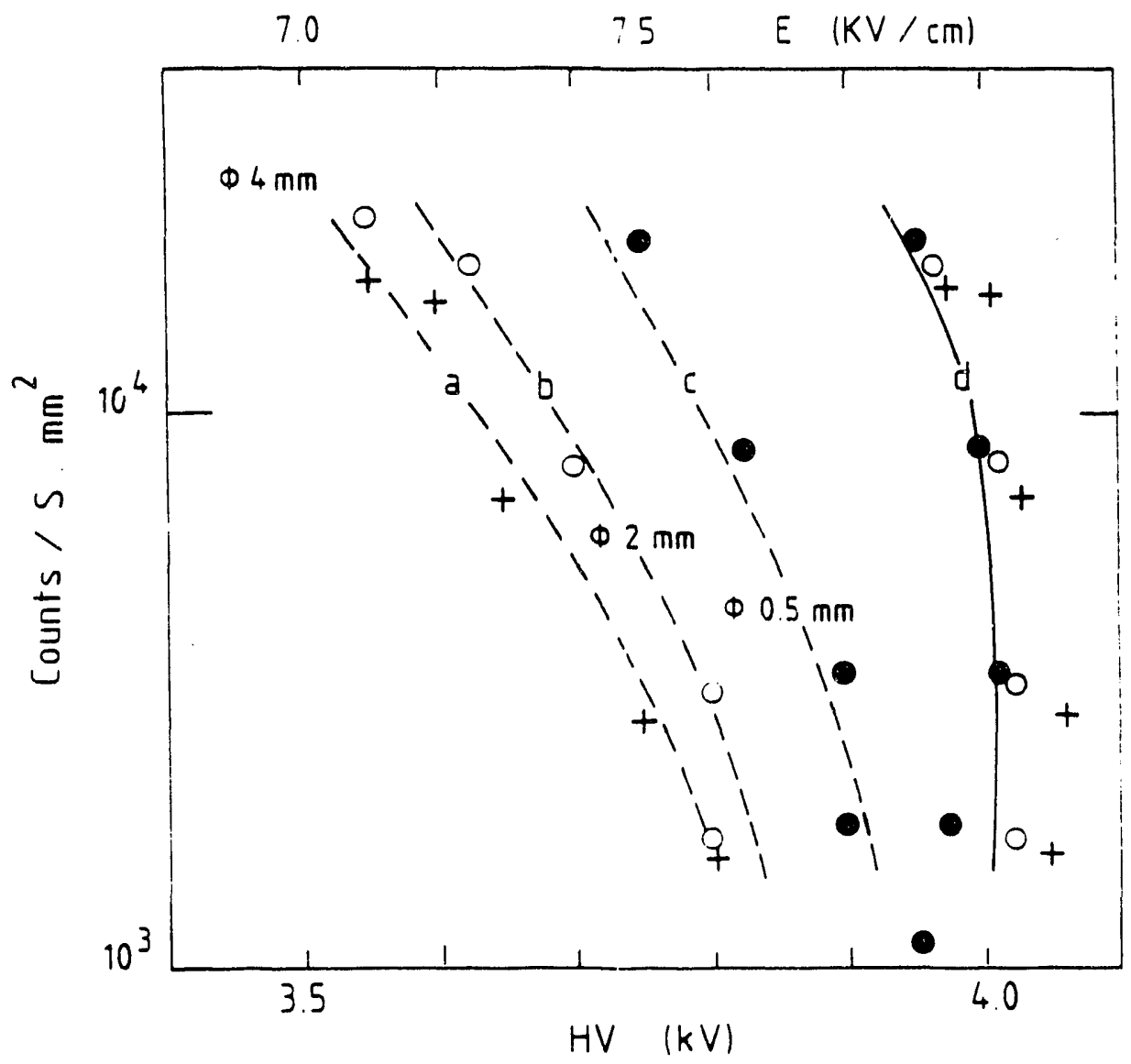

Fig. 8 Count rate dependence (without sparks) as a function of active area and high voltage for a PPAC [17]. 

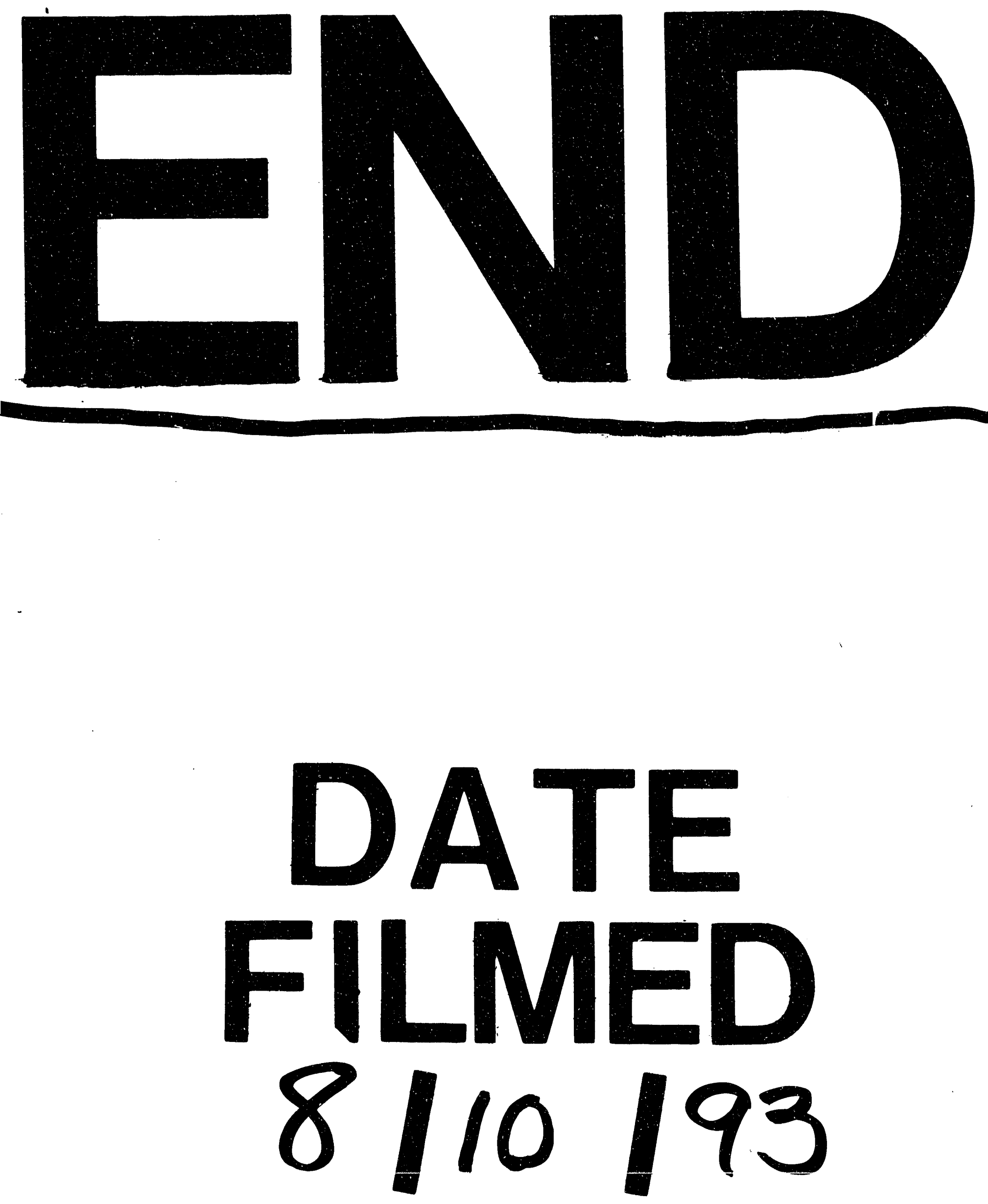


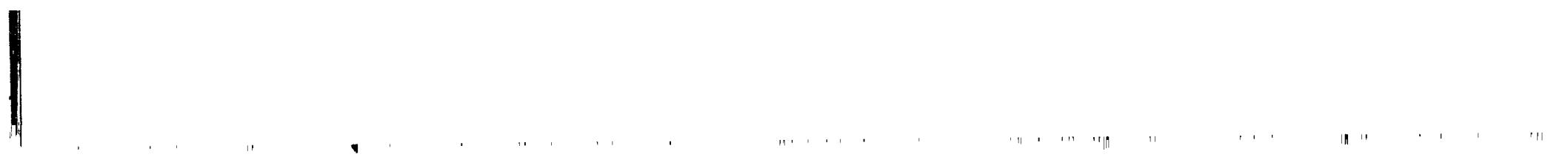

